\title{
Agrochemical condition and nutrition balance of newly irrigated light gray soils of Uzbekistan
}

\author{
Jakhongir Kuziev ${ }^{1, *}$, Sherali Mansurov ${ }^{1}$, Murod Karimov $^{2}$, and Aslbek Kholikulov ${ }^{1}$ \\ ${ }^{1}$ Research Institute of Soil Science and Agrochemistry, Kamarniso str., Tashkent, Uzbekistan \\ ${ }^{2}$ Tashkent State Agrarian University, University str., 2, Tashkent province, Uzbekistan, 100140
}

\begin{abstract}
This paper notes the geographical location, soil and climatic conditions, geomorphological and geological structure of Jizzakh province, as well as the agrochemical status of newly irrigated light gray soils formed in Arnasay district of the province, nutrients and their balance in the autumn glaciers. According to the results of chemical analysis, it was found that the mechanical composition of the studied soils consists of light sandy and loamy soils, in which fine sand particles $(0.5-0.05 \%)$ predominate. The study showed that in the driving layers of newly irrigated light gray soils, humus was present at $0.823-0.936 \%$, total nitrogen at $0.059-0.084 \%$, total phosphorus at $0.096-0.135 \%$, and total potassium at $1.05-1.36 \%$, humus and mobile nutrients. It was noted that they belong to very low and low-income groups according to their level. The amount of mineral and local fertilizers applied to winter wheat, the residues of winter wheat and the amount of crop and stem (straw) grown in relation to the amounts that fall into the soil by natural means is high $(\mathrm{N}-15.1 \mathrm{~kg} / \mathrm{ha}, \mathrm{P}-3$, $6 \mathrm{~kg} / \mathrm{ha}, \mathrm{K}-34.4 \mathrm{~kg} / \mathrm{ha})$.
\end{abstract}

\section{Introduction}

In recent years, as a result of rapid use of land resources around the world, including in Uzbekistan, there has been a decrease in humus and nutrients in soils [1, 12]. As a result, there is a lack of some elements in the soil for the nutrition of agricultural crops. One of the main reasons for this is the violation of the law of reduction, as a result of the irreversible release of nutrients from the soil every year, and in some parts, irreversible release of nutrients $[1,2,13]$. As a result, a number of negative processes are allowed to develop in the soil. In particular, the resistance of soils to anthropogenic impacts is declining, erosion processes are intensifying, physicochemical and agrochemical properties are deteriorating, and the aggregate condition (composition) of agronomic value is deteriorating. In short, it is clear that soils are being degraded $[3,13,14]$.

Therefore, in order to increase soil fertility, first of all, to determine their current state, to ensure their equality by differentiating the nutrient content of soils distributed in the field contours, to determine high-yield agricultural crops suitable for each soil-climatic zone, based on the principles of agroecological zoning. It is necessary to introduce the production of the most optimal agro-technologies with a comprehensive analysis of placement,

* Corresponding author: mmjahongir81@gmail.com 
cultivation of high and ecologically clean food, modern fertilizer application systems for intensive farming, crop rotation and a number of other agro-technical measures [4, 12].

This is due to the fact that in recent years the population has been growing from year to year. For example, according to the United Nations, the world's population will grow from 7.2 billion to 12 billion (by the end of the century) [4]. In 2008, the world's population was 6.5 billion, in 2011 it was 7 billion, and by 2100 . It is estimated that it will reach 12 billion $[5,6]$. Researchers also note that by 2050 , agricultural production will increase by $70-80 \%$. This requires more rational and efficient use of land resources. Because land resources are a national treasure not only in Uzbekistan, but also around the world and are the main source of human progress. Also, the globalization of today's economy, the innovative development of equipment and information technology, defines certain tasks and decisions for the digital economy of all countries, including Uzbekistan [7, 11, 13]. This requires control and means attracting and developing modern resource-saving technologies in all sectors of agriculture, raising production to a qualitatively new level, obtaining high-quality and weighty crops, increasing exports, protecting the environment from negative processes, as well as maintaining soil fertility $[4,10,15]$.

Today, there are $133,818,273 \mathrm{~km}^{2}(13,381.8$ million ha) in the world, of which irrigated land is $2,907,700 \mathrm{~km}^{2}(290.77$ million ha) or $2.2 \%$ of the total area. This indicates the need for efficient use of each hectare, the provision of ecologically clean food to the population, the control of each square meter and the constant increase of soil fertility $[8,9,15]$.

Therefore, the main purpose of this study is to determine the current state of the agrochemical properties of irrigated soils, to study the balance of nutrients and the reasons for the decline in soil fertility.

\section{Materials and methods}

Uzbekistan is located in the central part of Central Asia at $41^{0}$ north latitude and $64^{0}$ east longitude. Jizzakh province, where the study was conducted, is located in the center of the Republic, the province is located in the natural latitude $41^{\circ} 20^{\prime}$ north latitude and $69^{\circ} 20^{\prime}$ east longitude. The province borders with Kazakhstan northeast and the Syrdarya province, southwest with the Samarkand and Navoi provinces, and with Tajikistan southeast $[4,11]$.

As of January 1, 2020, the area of land within the administrative boundaries of Jizzakh province is 2,121.1 thousand hectares, the total area of agricultural land is 2,117.8 thousand hectares, of which irrigated agricultural land is 295.3 thousand hectares or $13.9 \%$ of the total area [4]. The province has light brown meadow steppe soils (1\%), brown soils (10\%), dark gray soils (13\%), typical gray soils (23\%), light gray soils $(7 \%)$, brown soils, barren soils. and other soils (36\%) [11]. $0.44 \%$ of the soils distributed in the province are clayey, $7.13 \%$ heavy, $49.56 \%$ medium, and $32.52 \%$ light sandy, $8.13 \%$ sandy and $2.15 \%$ sandy mechanical soils. Also, the amount of humus in these soils is very low and low in the district irrigated crop area $-80 \%$, ie less than $1 \%, 20 \%(1.1-2 \%)$ is provided on average.

The relief of Arnasay district, where the research was conducted, consists mainly of plains and low plains. The exposition gradually rises from north and northwest, south and southwest. The climate is sharply continental, with an average January temperature of $-5^{\circ} \mathrm{C}$ and an average July temperature of around $30^{\circ} \mathrm{C}$ [11].

Due to the peculiarities of the climate and hydrogeological conditions of the Arnasay lowlands, the vegetation cover of these lands is also different due to the complex structure of the surface crust. Another distinctive feature of the province is the stable heat, drought and winter instability. The average temperature ranges from $12.4^{\circ} \mathrm{C}$ to $14.2^{\circ} \mathrm{C}$ (perennial monthly data), and the annual low temperature is north and northeast [11].

In Arnasay district, mainly gray-meadow and light gray soils are distributed, $81 \%$ of the total irrigated agricultural land is gray-meadow and $19 \%$ is light gray soils. According to 
the mechanical composition of these soils, $0.4 \%$ consists of heavy sandy, $18 \%$ medium, $48 \%$ light sandy, 29\% sandy, 5\% sandy mechanical composition [4].

Point \#185 of "Iqtisodchi Asrorbek" farm in Arnasay district were selected as a research area. Mechanical composition of the genetic layers of the soil profile $0-134 \mathrm{~cm}$ are slightly sandy, the lower 134-242 cm layers are sandy (Table 1), the soil quality index was estimated as 53 points from 100 (weakly saline).

Table 1. Mechanical composition of newly irrigated light gray soils

\begin{tabular}{|c|c|c|c|c|c|c|c|c|c|c|}
\hline \multirow[b]{2}{*}{ \# } & \multirow[b]{2}{*}{$\begin{array}{c}\text { Layer } \\
\text { depth, } \\
\text { cm }\end{array}$} & \multicolumn{8}{|c|}{ Soil particles in $\%$, in $\mathrm{mm}$} & \multirow[b]{2}{*}{ Soil } \\
\hline & & $>0.25$ & $\begin{array}{c}0.25- \\
0.1\end{array}$ & $\begin{array}{l}0.1- \\
0.05\end{array}$ & $\begin{array}{c}\text { 0.05- } \\
0.01\end{array}$ & $\begin{array}{l}\text { 0.01- } \\
0.005\end{array}$ & $\begin{array}{c}0.005- \\
0.001\end{array}$ & $<0.001$ & $\begin{array}{c}\text { Physical } \\
\text { mud } \\
(<0.01 \\
\text { mm })\end{array}$ & \\
\hline \multirow{6}{*}{ 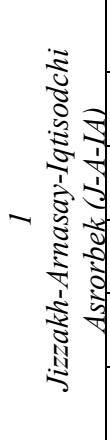 } & $0-31$ & 0.7 & 0.3 & 48.6 & 24.5 & 11.5 & 8.3 & 6.1 & 25.9 & $\begin{array}{l}\text { Light } \\
\text { sandy }\end{array}$ \\
\hline & $31-49$ & 0.9 & 0.5 & 46.5 & 23.5 & 14.2 & 9.3 & 5.1 & 28.6 & $\begin{array}{l}\text { Light } \\
\text { sandy }\end{array}$ \\
\hline & $49-93$ & 1.1 & 0.9 & 46.2 & 25.7 & 12.8 & 8.4 & 4.9 & 26.1 & $\begin{array}{l}\text { Light } \\
\text { sandy }\end{array}$ \\
\hline & $\begin{array}{l}93- \\
134 \\
\end{array}$ & 1.2 & 0.5 & 44.3 & 28.4 & 11.6 & 9.3 & 4.7 & 25.6 & $\begin{array}{l}\text { Light } \\
\text { sandy }\end{array}$ \\
\hline & $\begin{array}{l}134- \\
187\end{array}$ & 4.9 & 1.6 & 53.9 & 20.6 & 8.3 & 4.7 & 5.9 & 18.9 & Sandy \\
\hline & $\begin{array}{l}187- \\
242 \\
\end{array}$ & 5.3 & 1.4 & 54.1 & 21.2 & 9.3 & 3.9 & 4.8 & 18.0 & Sandy \\
\hline
\end{tabular}

Field research, soil and plant sampling, agrochemical analysis, phenological observations were carried out on the basis of generally accepted methodological guidelines in the field of soil science and agrochemistry. In particular, the Guidelines for the implementation of chemical and agrophysical analyzes in the monitoring of land [1], as well as special "Application of mineral and local fertilizers in cotton" [2], "Methods of field experiments", and "Technology of high yields in cotton" [3].

\section{Results and discussion}

The content of humus in the driving and subsoil layers of the soils of this pilot area ranged from $0.741-0.936 \%$, total nitrogen to $0.054-0.084 \%$, total phosphorus to 0.091 $0.135 \%$, total potassium to $0.86-1.36 \%$, and they gradually decreased towards the lower layers (Table 2). 
Table 2. Agrochemical properties of newly irrigated light gray soils

\begin{tabular}{|c|c|c|c|c|c|c|c|c|c|}
\hline \multirow{3}{*}{ \# } & \multirow{3}{*}{ 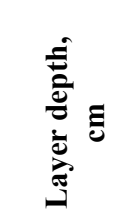 } & \multirow{3}{*}{$\begin{array}{l}\stackrel{\partial}{0} \\
\stackrel{\hat{\Xi}}{\Xi} \\
\stackrel{\Xi}{\Xi}\end{array}$} & \multirow{3}{*}{$\begin{array}{l}0^{\circ} \\
\frac{z}{a} \\
\frac{\pi}{0}\end{array}$} & \multirow{3}{*}{ ن } & \multicolumn{5}{|c|}{ Fertilizers } \\
\hline & & & & & \multicolumn{2}{|c|}{ gross, $\%$} & \multicolumn{3}{|c|}{ reactive, $\mathrm{mg} / \mathrm{kg}$} \\
\hline & & & & & $\mathbf{P}$ & $\mathbf{K}$ & $\mathrm{N}-\mathrm{NO}_{3}$ & $\mathbf{P}_{2} \mathrm{O}_{5}$ & $\mathbf{K}_{2} \mathbf{O}$ \\
\hline \multicolumn{10}{|c|}{ Point \#185 of "Iqtisodchi Asrorbek" in massif "Ferghana" } \\
\hline \multirow{6}{*}{$\begin{array}{c}1 \\
\text { J-A-IA }\end{array}$} & $0-31$ & 0.895 & 0.084 & 6.2 & 0.118 & 1.36 & 16.5 & 13.6 & 194 \\
\hline & $31-49$ & 0.842 & 0.073 & 6.7 & 0.109 & 1.22 & 12.4 & 11.9 & 178 \\
\hline & $49-93$ & 0.725 & 0.068 & 6.2 & 0.093 & 1.05 & 11.3 & 9.4 & 165 \\
\hline & $93-134$ & 0.608 & 0.054 & 6.5 & 0.091 & 0.96 & 9.2 & 8.6 & 157 \\
\hline & 134-187 & 0.432 & 0.044 & 5.7 & 0.082 & 0.84 & 6.1 & 5.3 & 136 \\
\hline & $187-242$ & 0.267 & 0.029 & 5.3 & 0.074 & 0.69 & 4.3 & 3.6 & 124 \\
\hline \multirow{5}{*}{$\begin{array}{c}2 \\
\text { J-A-IA }\end{array}$} & $0-32$ & 0.874 & 0.083 & 6.1 & 0.122 & 1.25 & 12.4 & 14.2 & 208 \\
\hline & $32-55$ & 0.823 & 0.071 & 6.7 & 0.104 & 1.06 & 11.9 & 11.9 & 189 \\
\hline & $55-98$ & 0.742 & 0.063 & 6.8 & 0.097 & 0.89 & 9.3 & 9.3 & 174 \\
\hline & $98-143$ & 0.639 & 0.055 & 6.7 & 0.085 & 0.77 & 5.6 & 7.4 & 156 \\
\hline & 143-197 & 0.521 & 0.047 & 6.4 & 0.081 & 0.66 & 4.9 & 6.3 & 132 \\
\hline \multirow{4}{*}{$\begin{array}{c}3 \\
\text { J-A-IA }\end{array}$} & $0-30$ & 0.844 & 0.059 & 8.3 & 0.135 & 1.05 & 14.6 & 13.5 & 241 \\
\hline & $30-48$ & 0.799 & 0.054 & 8.6 & 0.121 & 0.99 & 11.2 & 12.4 & 207 \\
\hline & 48-78 & 0.712 & 0.047 & 8.8 & 0.111 & 0.91 & 9.3 & 10.9 & 185 \\
\hline & $78-110$ & 0.653 & 0.045 & 8.4 & 0.096 & 0.85 & 6.7 & 8.3 & 158 \\
\hline \multirow{6}{*}{$\begin{array}{c}4 \\
\text { J-A-IA }\end{array}$} & $110-154$ & 0.524 & 0.035 & 8.7 & 0.091 & 0.84 & 5.1 & 7.4 & 141 \\
\hline & $0-30$ & 0.823 & 0.074 & 6.5 & 0.128 & 1.32 & 14.8 & 14.9 & 205 \\
\hline & $30-46$ & 0.741 & 0.069 & 6.2 & 0.120 & 1.21 & 13.6 & 11.3 & 183 \\
\hline & $46-83$ & 0.639 & 0.054 & 6.9 & 0.102 & 1.03 & 10.5 & 9.3 & 164 \\
\hline & $83-115$ & 0.525 & 0.047 & 6.5 & 0.089 & 0.85 & 4.9 & 8.4 & 157 \\
\hline & $115-145$ & 0.346 & 0.039 & 5.1 & 0.077 & 0.74 & 4.2 & 6.3 & 124 \\
\hline \multirow{5}{*}{$\begin{array}{c}5 \\
\text { J-A-IA }\end{array}$} & $0-24$ & 0.936 & 0.071 & 7.6 & 0.096 & 1.05 & 17.6 & 16.4 & 197 \\
\hline & $24-51$ & 0.857 & 0.069 & 7.2 & 0.091 & 0.86 & 12.7 & 14.5 & 174 \\
\hline & $51-82$ & 0.741 & 0.055 & 7.8 & 0.085 & 0.74 & 9.3 & 10.3 & 169 \\
\hline & $82-125$ & 0.638 & 0.045 & 8.2 & 0.074 & 0.66 & 6.4 & 6.9 & 124 \\
\hline & $125-204$ & 0.458 & 0.033 & 8.0 & 0.066 & 0.61 & 5.1 & 8.4 & 93 \\
\hline
\end{tabular}

Reactive nitrogen, phosphorus, and potassium belong mainly to groups that are very low and low, moderately present in some drive layers $(205-241 \mathrm{mg} / \mathrm{kg}$ with potassium) (Table 2).

After studying the mechanical composition of the pilot area, the weight of the crucible, humus and nutrients, reserves of soil in layers of $0-30 \mathrm{~cm}, 0-50 \mathrm{~cm}, 0-100 \mathrm{~cm}$ were identified (Table 3). 
Table 3. Humus and nutrient reserves of the studied pilot areas

\begin{tabular}{|c|c|c|c|c|c|c|c|c|c|}
\hline \multirow{3}{*}{\multicolumn{2}{|c|}{$\begin{array}{c}\text { Mechanical } \\
\text { composition and bulk } \\
\text { density of soils }\end{array}$}} & \multirow{3}{*}{$\begin{array}{c}\text { Layer } \\
\text { depth, } \\
\text { cm }\end{array}$} & \multirow{3}{*}{$\begin{array}{l}\text { Humus, } \\
\text { tons/ha }\end{array}$} & \multicolumn{6}{|c|}{ Fertilizer } \\
\hline & & & & \multicolumn{3}{|c|}{ Total, tons/ha } & \multicolumn{3}{|c|}{ Reactive form, tons/ha } \\
\hline & & & & $\mathbf{N}$ & $\mathbf{P}$ & $\mathbf{K}$ & $\mathrm{N}^{-\mathrm{NO}_{3}}$ & $\mathbf{P}_{2} \mathbf{O}_{5}$ & $\mathbf{K}_{2} \mathbf{O}$ \\
\hline \multicolumn{10}{|c|}{ Newly irrigated light gray soils } \\
\hline Light sandy & 1.30 & $0-30$ & 34.9 & 3.3 & 4.6 & 53.0 & 64 & 53 & 757 \\
\hline Light sandy & 1.35 & $0-50$ & 57.4 & 5.2 & 7.5 & 85.8 & 98 & 85 & 1235 \\
\hline Light sandy & 1.25 & $0-100$ & 101.7 & 9.4 & 13.3 & 150.6 & 167 & 143 & 2259 \\
\hline
\end{tabular}

Accordingly, in the 0-30 cm layer of irrigated light gray soils formed in the studied pilot area, humus reserves are 34.9 tons/ha, total nitrogen is 3.3 tons/ha, total phosphorus is 4.6 tons/ha, and total potassium is 53.0 . tons/ha, mobile nitrogen $64 \mathrm{~kg} / \mathrm{ha}$, mobile phosphorus $53 \mathrm{~kg} / \mathrm{ha}$, exchangeable potassium $757 \mathrm{~kg} / \mathrm{ha}$. Reserves of humus and nutrients in the 0-50 and $0-100 \mathrm{~cm}$ layers are higher than in the $0-30 \mathrm{~cm}$ layer. It was noted that while the nutrient elements gradually decreased from the drive layers to the lower layers, their reserves were high. This is because their reserves are relatively high due to the bulk density and thickness of the soils (Table 3).

The amount of mobile nutrients in the soil was determined on the basis of the following equation (1):

$$
M c=(d x h) / 10
$$

After analyzing the data on humus, total and mobile nitrogen, phosphorus, potassium and mechanical composition of the genetic layers of the soils distributed in the pilot area, the amount of nutrients and their balances in winter wheat grown in this pilot area were studied.

According to the chemical analysis of plant samples taken at the end of the growing season from winter wheat grown in the pilot area, the grains contained $1.75 \%$ nitrogen, $0.43 \%$ phosphorus, $0.30 \%$ potassium. With these grains, $73.1 \mathrm{~kg}$ of nitrogen, $17.9 \mathrm{~kg}$ of phosphorus and $12.4 \mathrm{~kg}$ of potassium per hectare are absorbed and it is irreversibly excreted (Table 4).

Table 4. Humus and nutrient reserves of the studied pilot areas

\begin{tabular}{|c|c|c|c|c|c|c|}
\hline \multicolumn{7}{|c|}{ Winter wheat } \\
\hline \multicolumn{4}{|c|}{ In components of a winter wheat, $\%$} & \multicolumn{3}{|c|}{$\begin{array}{l}\text { Absorption from } 1 \text { ha, } \\
\mathrm{kg} / \mathrm{ha}\end{array}$} \\
\hline Parts & $\mathrm{N}$ & $\mathrm{P}$ & $\mathrm{K}$ & $\mathrm{N}$ & $\mathrm{P}$ & $\mathrm{K}$ \\
\hline \multicolumn{7}{|c|}{$\begin{array}{l}\text { A pilot area with a high level of productivity in Arnasay district of } \\
\text { Jizzakh province }\end{array}$} \\
\hline Seed & 1.75 & 0.43 & 0.30 & 73,1 & 17,9 & 12,4 \\
\hline Cocoon & 0.58 & 0.31 & 0.40 & 9,9 & 5,4 & 6,8 \\
\hline Stem-leaf (straw) & 1.89 & 0.56 & 2.01 & 90,0 & 26,8 & 95,6 \\
\hline Root & 0.41 & 0.30 & 0.47 & 16,7 & 12,1 & 19,0 \\
\hline \multicolumn{4}{|c|}{ Total } & 189.8 & 62.2 & 133.7 \\
\hline
\end{tabular}


Winter wheat grown on the pilot site received the following amounts of minerals and nutrients locally and naturally in one season:

$\mathrm{N}-148 \mathrm{~kg} / \mathrm{ha}, \mathrm{P}-41.1 \mathrm{~kg} / \mathrm{ha}, \mathrm{K}-73.6 \mathrm{~kg} / \mathrm{ha}$;

However, when comparing incoming and outgoing quantities, a mostly negative situation was observed in the pilot area. In this case, the negative state of nutrients was noted when comparing the amounts of mineral and local fertilizers applied to the soil, the remnants of winter wheat and naturally occurring nutrients and the amount released by the crop and stems (straw) (Table 5).

Table 5. Balance of nutrients applied to winter wheat grown under the conditions of the studied soils and with their parts, $\mathrm{kg} / \mathrm{ha}$

(Point \#185, Arnasay district of Jizzakh province)

\begin{tabular}{|c|c|c|c|c|}
\hline \multicolumn{5}{|c|}{ Winter wheat } \\
\hline \multicolumn{5}{|c|}{ Incoming proportion per soil parts } \\
\hline \multicolumn{2}{|c|}{ Income and expenditure balance items } & $\mathrm{N}$ & $\mathrm{P}$ & $\mathrm{K}$ \\
\hline \multirow{2}{*}{$\begin{array}{l}\text { With mineral and local } \\
\text { fertilizers applied to the soil }\end{array}$} & With mineral fertilizers & 68.0 & 5.0 & 15.0 \\
\hline & With local fertilizers & 2.9 & 0.9 & 4.5 \\
\hline \multirow{2}{*}{ With parts of wheat } & With cocoons & 9.9 & 5.4 & 6.8 \\
\hline & With roots & 16.7 & 12.1 & 19.0 \\
\hline \multirow{4}{*}{ In a natural phenomenon } & In the $0-30 \mathrm{~cm}$ layer of soil & 32.0 & 15.0 & 27.0 \\
\hline & With sowed seeds & 12.1 & 0.7 & - \\
\hline & With irrigation water & 3.0 & - & - \\
\hline & With precipitation & 0.8 & 0.5 & 0.7 \\
\hline \multicolumn{2}{|c|}{ Total } & 148.0 & 41.1 & 73.6 \\
\hline \multicolumn{5}{|c|}{ Outgoing proportion from soil } \\
\hline \multicolumn{2}{|c|}{ With the harvested part (grain) of wheat } & 73,1 & 17.9 & 12.4 \\
\hline \multicolumn{2}{|c|}{ With stem-leaf (straw) of wheat } & 90,0 & 26.8 & 95.6 \\
\hline \multicolumn{2}{|c|}{ Total } & 163.1 & 44.7 & 108.0 \\
\hline \multicolumn{2}{|c|}{ Difference } & -15.1 & -3.6 & -34.4 \\
\hline
\end{tabular}

From the above data, it can be seen that one of the main reasons for the varying degrees of degradation of irrigated agricultural land, which is the golden fund of agriculture, is the negative impact on the agrochemical properties of soils, reserves in genetic layers. In addition, as crops absorb as many nutrients from the soil as possible, it is possible for the soil to move from a low-nutrient to a very low-income group.

The International Institute of Plant Nutrition has studied the level of nutrient availability in the soil and their balance on the example of some countries that use mineral fertilizers. In Brazil, India, China, Russia, Bulgaria, and the United States, soils are divided into three groups: negative, positive, and zero, taking into account the level of nitrogen, phosphorus, and potassium in the soil and the nutrient balance [5-7, 10].

According to the data [4] in the conditions of the Republic of Uzbekistan, a negative balance of nutrients was observed during alternating and chronic cotton planting. At the same time, in the control variant $-14.9 \mathrm{~kg} / \mathrm{ha}$ nitrogen, $-14.8 \mathrm{~kg} / \mathrm{ha}$ phosphorus and -46.0 $\mathrm{kg} / \mathrm{ha}$ potassium were additionally removed from the soil, in the mineral fertilizer variants the nitrogen and phosphorus balance was positive $(+51.4:+71.6)$, but the potassium balance was found to be negative $(-60.5 \mathrm{~kg} / \mathrm{ha})$, i.e., the yield was higher than that of the input.

Accordingly, when cultivating wheat in gray forest and black soil conditions, - $71.5-80.5$ $\mathrm{kg} / \mathrm{ha}$ in the control variant and $-31.4-82.7 \mathrm{~kg} / \mathrm{ha}$ in the remaining variants, respectively 23.3-37.0; -28.5-48.0 kg/ha phosphorus and -64.0-77.4; -24.2-106.7 kg/ha, and potassium 
was released by the crop. A similar situation was observed in sugar beet, corn, sunflower, peas and oats $[5,10]$.

In the CIS countries, including Armenia - $+74.9 \%$ nitrogen, $-41.3 \%$ phosphorus and $72.4 \%$ potassium, $+104 ;-11.1$; -26.0 in Belarus, respectively; In Kazakhstan -88.4; -67.0; 91.5; In Russia - -42.8; -28.5; -62.8; In Ukraine - 65.0; -41.0; -61.0; from the amount of nutrients included in the soils, the proportion of cuttings was noted to be large. According to the author, only in Estonia $+5.4 ;+49.4 ;+0.9 \%$ positive was recorded $[4,6]$.

In the first control variant, when mineral and local fertilizers were applied together $\left(\mathrm{N}_{40} \mathrm{P}_{36} \mathrm{~K}_{40}+6\right.$ tons/ha fertilizer), cereals and beets were treated with nutrients added to the soil in one season $[5,6]$. It was noted that the amount of nutrients that go out with the harvest is high. In other words, $-74.3 \mathrm{~kg} / \mathrm{ha}$ of nitrogen was added in the control variant, and $-66.8 \mathrm{~kg} / \mathrm{ha}$ in the variant of mineral and local fertilizers.

\section{Conclusion}

The degree or amount of humus and nutrient availability of newly irrigated light gray soils studied is important in determining their reserves in their genetic layers and thereby determining annual fertilizer norms. It was found that these irrigated soils belong to the groups of very low, low and medium supply of nutrients. According to the mechanical composition of the pilot areas, they consist of light sandy and loamy soils and are dominated by fine sand particles $(0.1-0.05 \%)$. In the drive layers of these irrigated light gray soils, and humus was recorded at $0.823-0.936 \%$, total nitrogen at $0.059-0.084 \%$, total phosphorus at $0.093-0.135 \%$, and total potassium at $1.05-1.36 \%$. In the genetic layer, nutrients have been steadily declining from the upper drive layers to the lower ones. The studied irrigated light gray soils were provided with very little $(<0.4 \%)$ and low $(0.41-$ $0.8 \%$ ) humus.

When winter wheat yielded an average of $49 \mathrm{ts} / \mathrm{ha}, 163.1 \mathrm{~kg}$ of nitrogen, $44.7 \mathrm{~kg}$ of phosphorus and $108.0 \mathrm{~kg}$ of potassium elements were extracted from the soil with grain and stems (straw) per hectare. In one season, a total of $148 \mathrm{~kg} / \mathrm{ha}$ of nitrogen, $41 \mathrm{~kg} / \mathrm{ha}$ of phosphorus and $74 \mathrm{~kg} / \mathrm{ha}$ of potassium elements were applied to the soil by mineral and local fertilizers, parts of winter wheat and natural means. According to the nutrient balance of nutrients, a negative state of nutrients was recorded (N-15.1 kg/ha, P-3.6 kg/ha, K-34.4 $\mathrm{kg} / \mathrm{ha}$ ). This means that if soil fertility is not managed scientifically, it will inevitably change for the worse, ie the development and implementation of optimal mineral fertilizer standards in a science-based "soil-plant-fertilizer" system suitable for soil-climatic conditions to return nutrients to the soil and ensure sustainable yields.

\section{References}

1. Guidelines for chemical and agrophysical soil analysis in land monitoring, 441 (TAITI Press, Tashkent, 2004)

2. Recommendations for the use of mineral and local fertilizers in cotton, 24 (ALBIT Press, Tashkent, 2013)

3. Methods of conducting field experiments, 147 (UzPITI Press, Tashkent, 2017)

4. B. Shokirov, M. Mirakov, B. Murodov, High yield technology in cotton growing, 72 (Nasaf Press, Karshi, 2010)

5. E. M. Smaling, Ag. Ecosys. Env, 71-145 (2008) 
6. E. Paul, Fertilizer Outlook and Technology, 23-39 (2011)

7. W. F. Sheldrick, J. K. Syers, J. Lingard, Ag. Ecosys. Env. 94, 341-354 (2003)

8. B. Vanlauwe, J. Diels, N. Sanginga, R. Merckx, CABI Publishing, 716-721 (2002)

9. D. Sacco, M. Bassanino, C. Grignani, European Journal of Agronomy 20(1), 199-210 (2003)

10. R. F. Zhao, Agronomy Journal 98(4), 938-945 (2006)

11. R. Kulmatov, A. Taylakov, S. Khasanov, Environmental Science and Pollution Research, 1-11 (2021)

12. R. A. Kulmatov, S. A. Adilov, S. Khasanov, IOP Publishing 614(1), 012149 (2020)

13. S. Isaev, I. Begmatov, G. Goziev, S. Khasanov, IOP Publishing 883(1), 012080 (2020)

14. S. K. Isaev, R. U. Rakhmatov, S. S. Tadjiev, G. I. Goziev, S. Z. Khasanov, IOP Publishing 614(1), 012147 (2020)

15. J. Cobo, G. Dercon, G. Cadisch, Agriculture, ecosystems \& environment, 136(1), 1-15 (2010) 